\title{
Ageing in the margins: expectations of and struggles for 'a good place to grow old' among low-income older Minnesotans
}

\author{
Jessica M. Finlay ${ }^{1,2 *}$, Joseph E. Gaugler ${ }^{3}$ and Robert L. Kane ${ }^{4 \dagger}$ \\ ${ }^{1}$ Institute for Social Research, University of Michigan, Ann Arbor, Michigan, USA, ${ }^{2}$ Department of \\ Geography, Environment, and Society, University of Minnesota, Minneapolis, Minnesota, USA, ${ }^{3}$ School of \\ Public Health, University of Minnesota, Minneapolis, Minnesota, USA and ${ }^{4}$ Division of Health \& Policy \\ Management, University of Minnesota, Minneapolis, Minnesota, USA \\ *Corresponding author. Email: jmfinlay@umich.edu
}

(Accepted 30 August 2018; first published online 24 September 2018)

\begin{abstract}
What constitutes a 'good place to grow old'? This study aimed to characterise salient features of built and social environments that are essential to support low-income ageing residents. Seated and mobile interviews were conducted with community-dwelling older participants (aged 55-92, mean $=71$ years) in three distinct socio-economic and geographic samples of the Minneapolis (Minnesota, United States of America) metropolitan area. The interviews prompted participants to evaluate their homes and neighbourhoods, and probed for particular socio-spatial characteristics that impact residential wellbeing. Qualitative thematic analyses focused on 38 individuals living in subsidised housing and homeless shelters. Four interrelated themes encompassed essential residential qualities: (a) safety and comfort, (b) service access, (c) social connection, and (d) stimulation. These broad ideals, when achieved, enabled participants to cultivate residential wellbeing and fulfilling place attachment. Analyses of the empirical data complicate theoretical assumptions by recognising unequal access to, irregular opportunities for and potential dangers of place attachment. Rich descriptions of participant homelessness, health hazards, crime, lack of supportive infrastructure and social isolation illustrate how place attachment is not inherently positive or necessarily attainable; rather, it is problematic and can involve risk. This article extends geographical gerontology's address of sociospatial inequalities by focusing on disadvantaged ageing individuals.
\end{abstract}

Keywords: housing; poverty; place attachment; ageing in place; geographical gerontology; qualitative interviews

\section{Introduction}

At 78, healthy but floundering, I really would like to know more about us and how to cope - or how we could cope if we knew how ... [Because] I have been happy, but I'm having some concerns now. My neighbourhood doesn't feel as safe.

\footnotetext{
${ }^{\dagger}$ Deceased.
}

(c) Cambridge University Press 2018 
There's a house down the street that I'm pretty sure they're dealing drugs. [But] I still love North Minneapolis. I raised my kids in North Minneapolis. I love my home ... My kids are ready for me to move, but I'm not moving (Millie, 78, North Minneapolis ${ }^{1}$ )

Millie lived alone in a low-income part of the city where she struggled to drive to essential services, feared being robbed and experienced worrying memory lapses. Despite the challenges of a dilapidated multi-storey house on her arthritic joints, Millie insisted that she would only vacate her long-time home on a stretcher. Millie prioritised the comforting familiarity and independence of her house, valued nearby family and friends, and desired to remain rooted in her local African American community. She desperately wanted more information, resources and assistance for low-income seniors such as herself to live comfortably and safely at home.

Millie exemplifies the ageing population that is rapidly becoming more racially and socio-economically diverse. Minority populations over the age of 65 in the United States of America (USA) increased to 11.1 million in 2016 (23\% of those 65 and older) and are projected to expand to 21.1 million in 2030: an 89\% increase, in comparison to a $39 \%$ rise in White non-Hispanic populations. While the babyboomers are known for economic prosperity and spending power, over 4.6 million older adults (9.3\%) were below the official poverty level in 2016, and $14.5 \%$ below the Supplemental Poverty Measure (which includes medical out-of-pocket expenses). These numbers were higher for minority populations (e.g. $18.7 \%$ of African Americans), women (10.6\%) and those living alone (17.3\%; Administration for Community Living, 2018). Those over the age of 50 now make up 31 per cent of the homeless population (Nagourney, 2016). Despite the rapidly diversifying ageing population, the voices of marginalised elders are frequently overlooked. In order to address the knowledge gap, this article focuses on 38 low-income participants residing across a midwestern American metropolitan area. They represent a marginalised and often-ignored group who exist outside normative expectations of ageing in stable housing with secure financial resources.

The study aimed to identify built and social environmental characteristics that are essential to support low-income ageing residents. Qualitative fieldwork documented people and terrain that are often disregarded or marked as unimportant. In participant interview responses, four interrelated themes encompassed 'a good place to grow old': safety and comfort, service access, social connection and stimulation. Taken together, these qualities enabled participants to cultivate place attachment: an emotional connection to spaces that instill belonging and insider status. However, place attachment was not uniformly positive or attainable. It could generate risk, vulnerability, and harm in under-served and hazardous areas. The analyses, grounded in the realities of socio-economically disadvantaged older adults, intervene in assumptions of 'normal' and 'average' place attachment trajectories to generate greater reflexivity and sustained recognition of difference. Evidence of often-invisible crises and unspoken indignities critique and re-position the theory of place attachment given the harms and exclusions it can produce. This research questions underlying assumptions and blind spots in geographical gerontology. It aims to extend the discipline's address of socio-spatial injustice by focusing on 
vulnerable older people ageing 'in the margins' in degraded, under-served and unsafe residential environments.

\section{Theoretical perspectives on place attachment}

Scholars note the development of rich cognitive and affective ties to the places we live, and the cultivation of spatial attachment to very specific ideas of 'my place' and 'my home' (Wahl and Oswald, 2016). One's home and community ideally enable everyday life 'in place': the feeling of embedded identity, purpose and meaningful connection (Kyle and Chick, 2007; Scannell and Gifford, 2010). Everyday experiences in intimate physical settings generate defining 'memories, ideas, feelings, attitudes, values, preferences, meanings, and conceptions of behavior and experience' (Proshansky et al., 1983: 59). Sense-of-place is constructed and negotiated within everyday home and community contexts. We develop strong place identity by developing ties to family and community, owning or renting a home, and participating in local daily civic life (Hayden, 1995). This is how we transform spaces into meaningful places, and the process through which we develop local insider status (Hay, 1998). Insideness is the level to which individuals perceive that they belong 'in place' (Relph, 1976).

Theories of place attachment and place identity permeate theoretical and empirical scholarship of geographical gerontology. A sense of 'being in place' is essential to wellbeing in later life (Rowles, 2017). Rowles (1983) identifies three dimensions of place attachment: physical, social and autobiographical insideness. Physical insideness represents inherent body-awareness for details of the physical environment (e.g. the number of steps in a familiar stairwell, the location of a light switch in the dark). Social insideness refers to integration within local family and community networks. Autobiographical insideness incorporates not only present places, but also a series of remembered places accumulated over one's lifetime. Place attachment may at times seem to defy logic, such as a woman living alone in a run-down home far from her children. Though her husband is gone and children far away, the rooms are still 'inhabited' by her family who, years ago, made the house a vibrant place (Rowles, 1983). Strongly rooted place attachment may cause ageing individuals to remain 'in place' despite sub-optimal living conditions (Fang et al., 2016). Negotiations, risks and negatives of place attachment remain under-explored in geographical gerontology literature to date.

\section{Design and methods \\ Case study area recruitment}

In contrast to existing studies on affluent and resourced populations living in moderate climates, this study investigates ageing in a harsh continental climate and focuses on under-represented low-income and racially diverse older adults. Observations are based on three case study areas of the Minneapolis metropolitan area: Downtown Minneapolis, North Minneapolis and Eden Prairie (Table 1). The purposive design of the case studies was selected for socio-demographic and geographic characteristics (Finlay, 2018; Finlay and Kobayashi, 2018). Eden Prairie is a low-density, car-oriented suburb largely settled in the 1960s and 1970s. It is 


\begin{tabular}{|c|c|c|c|c|c|c|}
\hline & USA & Minnesota & $\begin{array}{l}\text { Hennepin } \\
\text { County }\end{array}$ & $\begin{array}{l}\text { Case study area 1: } \\
\text { Downtown Minneapolis }\end{array}$ & $\begin{array}{l}\text { Case study area } 2 \text { : } \\
\text { North Minneapolis }\end{array}$ & $\begin{array}{l}\text { Case study area } \\
\text { 3: Eden Prairie }\end{array}$ \\
\hline $\begin{array}{l}\text { Resident population } \\
\text { estimate }^{1}\end{array}$ & $318,857,056$ & $5,457,173$ & $1,212,064$ & 31,353 & 6,681 & 63,228 \\
\hline $\begin{array}{l}\text { Median gross rent (US \$), } \\
2010-2014^{1}\end{array}$ & 920 & 835 & 934 & 879 & 670 & 1,154 \\
\hline $\begin{array}{l}\text { Median household income } \\
\text { (US \$), 2010-2014 }\end{array}$ & 53,482 & 60,828 & 65,033 & 49,922 & 24,733 & 95,697 \\
\hline $\begin{array}{l}\text { Population aged } 65+\text { years } \\
(\%)^{2}\end{array}$ & 13 & 12.9 & 11.4 & 11 & 6.4 & 8.6 \\
\hline \multicolumn{7}{|l|}{$\begin{array}{l}\text { Race and Hispanic origin } \\
(\%):{ }^{1}\end{array}$} \\
\hline White & 62.1 & 81.4 & 70.3 & 64.3 & 11.7 & 81.7 \\
\hline Black & 13.2 & 5.9 & 12.6 & 20.2 & 53 & 5.6 \\
\hline Asian & 5.4 & 4.7 & 7.2 & 6.1 & 22.5 & 9.2 \\
\hline Hispanic or Latino & 17.4 & 5.1 & 6.8 & 4.9 & 8 & 3 \\
\hline Other $^{3}$ & 1.9 & 2.9 & 3.1 & 4.5 & 4.8 & 0.5 \\
\hline
\end{tabular}

Notes: 1. Population estimates from 1 July 2014 (data from US Census Bureau 2015). 2. Population estimates from 1 April 2010 (data from US Census Bureau 2015). 3. Other refers to American Indian and Alaska Native, Native Hawaiian and Other Pacific Islander, and Two or More Races. 
the wealthiest of the three case study areas with a median gross rent and household income well above the national average. Over 80 per cent of Eden Prairie residents identify as White (US Census Bureau, 2015). North Minneapolis is a mediumdensity part of the city principally settled by Jewish immigrants from Russia and Eastern Europe alongside African Americans in the early 1900s. Post-Second World War, the region became predominantly African American following 'White flight' of wealthier Jewish residents to the suburbs. A wave of Asian immigrants joined the community during the 1970s (Lamke, 2011). North Minneapolis has high levels of unemployment and socio-economic disadvantage, including household incomes substantially lower than the national average. Over half of residents identify as Black and nearly one-quarter identify as Asian. The final case study area, Downtown Minneapolis, is a high-density, pedestrian-oriented city centre. It is socio-economically polarised between affluent condominium-dwelling individuals and low-income populations residing in subsidised government housing and homeless shelters. The median gross rent and median household income are closest of the three case study areas to the national average. Nearly 65 per cent of residents identify as White and 20 per cent identify as Black (US Census Bureau, 2015).

The study was approved by the University of Minnesota Institutional Review Board. The first author (JF) employed non-probability sampling in each case study to recruit volunteers in response to project flyers and advertisements. Contacts at senior centres, community centres, church groups, community health fairs, housing services, civic organisations and social services helped to distribute flyers and advertise the study. Eligibility criteria included: over the age of $55,{ }^{2}$ not institutionalised in a care setting, residence in a case study area and demonstrated cognitive capacity to participate in the interview. The response to participate was outstanding, with over 300 people contacting JF to express interest. Respondents who met eligibility criteria were enrolled in order of response in each case study area (42 participants in Downtown Minneapolis, 42 in North Minneapolis, 41 in Eden Prairie). Recruitment concluded at 125 participants given that maximum capacity had been reached, and interviews were conducted from June to October 2015.

\section{Interviews}

Qualitative seated interviews were conducted by JF and a research assistant in participants' homes or a nearby public place of their choosing (e.g. coffee shop, senior centre). JF began with background questions to assess participants' demographics and living situation. Semi-structured questions considered daily routines, social interactions, service provision and perceived wellbeing. Participants evaluated their residential environments with prompts such as: Do you like living here? What do you think is good about your home and neighbourhood for older residents? What concerns do you have about your home and neighbourhood for older residents? What, if anything, could be improved in your home and neighbourhood to better meet your needs now and in the future? Participants were asked to describe their ideal ('dream') place to live as they age, and articulate what constitutes 'a good place to grow old'. 
Immediately following the seated interview, willing participants started the mobile interview: a short tour of the home and neighbourhood to show researchers nearby places and spaces of significance. Participants determined the route, speed and mode of travel to anywhere they thought appropriate for approximately 20 minutes. The majority of interviewees participated in mobile interviews $(\mathrm{N}=96)$ : most walked unaided $(\mathrm{N}=87)$, while the rest moved with a cane/walker or seated in a motorised wheelchair. Researchers used notebooks to record observations, a Global Positioning System-enabled watch to track the route and duration, and a digital camera to document features and scenery. JF and the research assistant individually wrote comprehensive notes within 24 hours to describe the interview setting, mobile interview route, participant behaviour, observed features, interactions and discussion. The mobile interviews enabled deeper investigation into the context of ageing: participants' biographies and everyday experiences framed by geography (Finlay and Bowman, 2017). Moving through space together revealed tacit knowledge and taken-for-granted practices of engaging with and connecting to one's local context. The method captured nuances of daily movement, practice and engagement that informed the analysis.

\section{Analyses}

Transcripts, photographs and field notes were organised using the software package NVivo (version 11). The seated interviews were transcribed verbatim by a professional service. After importing all documents to NVivo, JF organised the material by data source and unique participants. The data were thematically analysed using Braun and Clarke's (2006) six steps of thematic analysis: (a) familiarisation; (b) generation of initial codes; (c) search for themes; (d) review themes; (e) define and name themes; and (f) write up themes analysed. Through close readings of notes, JF and two research assistants compared interpretations and points of divergence to refine and clarify codes. Independently coding a sample of interviews checked for consistency in meaning and application of the codebook, and illuminated any differing interpretations via individual bias. After finalising the codebook, one research assistant coded all qualitative material. JF then reviewed the material to ensure completeness and accuracy, and added any additional coding. Member checking with participants, regular debriefing and audit trails (clear pathways detailing how the data were collected and managed) enhanced transparency and credibility (Marshall and Rossman, 2016). Iterative analyses continually seeking interpretation, alternative understandings and linkages led to saturation, whereby the themes were well-described by and fitting with the data (Dey, 1999).

\section{Participants}

The sub-sample of participants described in this article are the 38 individuals who lived in subsidised housing and homeless shelters (Table 2). These participants resided across all three case study areas (20 Downtown Minneapolis, eight North Minneapolis, ten Eden Prairie), were 55-92 years old and nearly three-quarters female. They self-identified across a range of races and ethnicities including White, Black/African American, Hispanic, Asian, African, Arabic, German and Polish. The majority of participants were single (never married), divorced/separated 
Table 2. Participant demographics and dwelling characteristics: entire sample and subsidised housing recipient sub-sample by case study area

\begin{tabular}{|c|c|c|c|c|c|c|}
\hline & \multicolumn{2}{|c|}{ Downtown Minneapolis } & \multicolumn{2}{|c|}{ North Minneapolis } & \multicolumn{2}{|c|}{ Eden Prairie } \\
\hline & $\begin{array}{l}\text { Entire } \\
\text { sample }\end{array}$ & $\begin{array}{l}\text { Subsidised } \\
\text { sub-sample }\end{array}$ & $\begin{array}{c}\text { Entire } \\
\text { sample }\end{array}$ & $\begin{array}{l}\text { Subsidised } \\
\text { sub-sample }\end{array}$ & $\begin{array}{l}\text { Entire } \\
\text { sample }\end{array}$ & $\begin{array}{l}\text { Subsidised } \\
\text { sub-sample }\end{array}$ \\
\hline $\mathrm{N}$ & 42 & 20 & 42 & 8 & 41 & 10 \\
\hline \multicolumn{7}{|l|}{ Age (in years): } \\
\hline Average/median & $71.6 / 72$ & $69.1 / 70$ & $69.6 / 70$ & $74.8 / 71.5$ & $73.0 / 73$ & $78 / 75$ \\
\hline Range & $55-91$ & $55-91$ & $56-91$ & $68-91$ & $60-92$ & $67-92$ \\
\hline \multicolumn{7}{|l|}{ Gender (\%): } \\
\hline Female & 61.9 & 65 & 76.2 & 75 & 65.9 & 90 \\
\hline Male & 38.1 & 35 & 23.8 & 25 & 34.1 & 10 \\
\hline \multicolumn{7}{|l|}{ Race/ethnicity (\%): } \\
\hline White & 73.8 & 50 & 16.7 & 12.5 & 80.5 & 50 \\
\hline Black/African American & 7.1 & 15 & 69.0 & 37.5 & - & - \\
\hline Hispanic/Latin American & 2.4 & 5 & - & - & - & - \\
\hline Asian & 2.4 & 5 & - & - & - & - \\
\hline Other $^{1}$ & 14.3 & 25 & 14.3 & 50 & 19.5 & 50 \\
\hline \multicolumn{7}{|l|}{ Education (\%): } \\
\hline Less than high school & - & - & 21.4 & 50 & - & - \\
\hline High school diploma & 52.4 & 85 & 47.6 & 37.5 & 48.8 & 90 \\
\hline Bachelor's degree & 21.4 & 15 & 16.7 & - & 34.1 & - \\
\hline Graduate degree & 26.2 & - & 14.3 & 12.5 & 17.1 & 10 \\
\hline
\end{tabular}


Table 2. (Continued.)

\begin{tabular}{|c|c|c|c|c|c|c|}
\hline & \multicolumn{2}{|c|}{ Downtown Minneapolis } & \multicolumn{2}{|c|}{ North Minneapolis } & \multicolumn{2}{|c|}{ Eden Prairie } \\
\hline & $\begin{array}{l}\text { Entire } \\
\text { sample }\end{array}$ & $\begin{array}{l}\text { Subsidised } \\
\text { sub-sample }\end{array}$ & $\begin{array}{l}\text { Entire } \\
\text { sample }\end{array}$ & $\begin{array}{l}\text { Subsidised } \\
\text { sub-sample }\end{array}$ & $\begin{array}{l}\text { Entire } \\
\text { sample }\end{array}$ & $\begin{array}{l}\text { Subsidised } \\
\text { sub-sample }\end{array}$ \\
\hline \multicolumn{7}{|l|}{ Employment status (\%): } \\
\hline Working & 21.4 & 25 & 19.0 & 12.5 & 17.1 & 0 \\
\hline Retired or unemployed & 78.6 & 75 & 81.0 & 87.5 & 82.9 & 100 \\
\hline \multicolumn{7}{|l|}{ Driving status (\%): } \\
\hline $\begin{array}{l}\text { Current valid driver's } \\
\text { licence }\end{array}$ & 69.0 & 50 & 76.2 & 25 & 95.1 & 80 \\
\hline $\begin{array}{l}\text { No (current) driver's } \\
\text { licence }\end{array}$ & 31.0 & 50 & 23.8 & 75 & 4.9 & 20 \\
\hline \multicolumn{7}{|l|}{ Marital status (\%): } \\
\hline Single (never married) & 35.7 & 55 & 14.3 & - & 2.4 & - \\
\hline Married (or common law) & 26.2 & - & 21.4 & 12.5 & 53.7 & - \\
\hline Divorced/separated & 31.0 & 40 & 33.3 & 37.5 & 29.3 & 70 \\
\hline Widowed/widower & 7.1 & 5 & 31.0 & 50 & 14.6 & 20 \\
\hline \multicolumn{7}{|l|}{ Living arrangement (\%): } \\
\hline Alone & 57.1 & 80 & 52.4 & 87.5 & 43.9 & 90 \\
\hline With a spouse/partner & 31.0 & - & 21.4 & 12.5 & 53.7 & 10 \\
\hline $\begin{array}{l}\text { With another family } \\
\text { member }\end{array}$ & - & - & 16.7 & - & 2.4 & - \\
\hline With a friend/roommate & 2.4 & - & 7.1 & - & - & - \\
\hline Other arrangement & 9.5 & 20 & 2.4 & - & - & - \\
\hline
\end{tabular}




\section{Length of residence (in \\ years):}

\begin{tabular}{|c|c|c|c|c|c|c|}
\hline Average/median & $11.04 / 8$ & $7.7 / 5.5$ & $18.19 / 15.5$ & $10.4 / 9$ & $18.95 / 19$ & $5.1 / 5.5$ \\
\hline Range & $0.5-48$ & $0.5-41$ & $0.5-45$ & $2-26$ & $0.5-50$ & $1.5-9$ \\
\hline \multicolumn{7}{|l|}{ Dwelling tenure $(\%)$ : } \\
\hline Own & 45.2 & - & 57.1 & - & 73.2 & - \\
\hline Market rental & 14.3 & - & 23.8 & - & 2.4 & - \\
\hline Subsidised housing & 47.6 & 100 & 19.0 & 100 & 24.4 & 100 \\
\hline
\end{tabular}

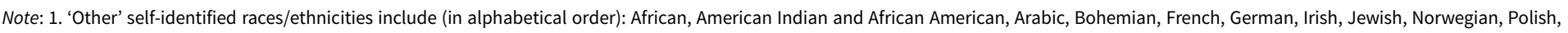
Scottish and Swedish. 
or widowed. Nearly all participants lived alone. Participants generally lived in their residential dwelling the longest in North Minneapolis (10.4 years average), followed by Downtown Minneapolis (7.7 years) and Eden Prairie (5.1 years). Six participants slept in a private or communal room of a homeless shelter.

\section{Striving to age well 'in place'}

Housing was not experienced simply as the presence of infrastructure and amenities; rather, it involved active and ongoing negotiation of physical and social dimensions of one's home and neighbourhood (Heatwole Shank and Cutchin, 2016). Participants sought comfortable places for regular rhythm, routine errands, and connection to oneself and others. Qualitative analyses of participant statements regarding desires and expectations of an ideal residential environment yielded four interrelated themes. First, participants stressed the importance of safety and comfort: a high sense of security from physical and emotional harm, and the ability to feel relaxed and comfortable. Second, access to services, facilities and recreational amenities were considered essential. Third, participants valued social connection including everyday interactions, social support and cohesion, and sense of community. Fourth, participants vocalised the need for stimulation: an environment with opportunities for fulfilling and meaningful activity. These four broad ideals, when achieved, enabled participants to cultivate residential wellbeing and place attachment. Participants exhibited broad-ranging suitability, daily hardships and challenges, and unexpected opportunities to age well 'in place'.

\section{Safety and comfort}

Feeling calm and safe in one's residential environment were considered essential. This encompassed sense of security (e.g. from crime and abuse), personal safety (e.g. from falls), and the ability to feel comfortable and relaxed.

\section{Physical safety}

At the scale of the neighbourhood, Downtown Minneapolis participants were the most attentive to micro-features of the surrounding environment. Noted elements included heavy traffic, uneven pavement, brief crosswalk timing and seasonal snow piles. Participants such as Trudy explained the stress and danger of navigating difficult terrain:

When you cross the street at the corners, you've got to climb the snow mounds. And then when you get on the snow mounds, it's icy ... It's like the city doesn't care that there are senior people and disabled people. (Trudy, 60, Downtown Minneapolis)

Trudy felt worn down by physical struggles around her building and neighbourhood. The walkway of her apartment entrance was treacherous given its uneven surface and slick bricks. After several falls while accessing disability transit, Trudy requested to switch her pick-up location to the back door. She taught herself to navigate the three steps with a walker while laden with groceries and house 
supplies. Trudy and others enhanced physical insideness (Rowles, 1983) through proactive steps. Frank (77, Downtown Minneapolis) taught himself the safest route to commute to and from the senior centre. He learned exactly where the icy spots were to avoid, and memorised the location of benches along his commute to rest. With limited access to cars, participants like Frank relied heavily on buses and 'skyways' (indoor pathways) to shield from weather and dangerous street traffic.

The older housing stock of North Minneapolis posed physical safety hazards to residents as their dwellings literally aged around them. Participants worried about their multi-storey houses and being unable to afford necessary modifications such as grab bars, sturdy ramps and accessible furniture. Some participants implemented low-cost strategies to boost personal safety, including de-cluttering to remove tripping hazards, putting a chair in the shower and wearing a fall pendant. They relied on physical insideness by memorising home layouts and knowing spaces with intimate body-awareness (Rowles, 1983). Often unable to afford home improvements, participants pointed with concern to crumbling stairs, mould, peeling paint and poor ventilation that posed health and fire hazards. They could not afford to hire services to remain safely at home, including cleaning, handy work, yardwork and home-based care. Participants weighed the benefits of remaining in their familiar home and neighbourhood with the escalating risk of falling, burdensome home maintenance and health hazards.

\section{Instability and emotional insecurity}

Long-time renters, homeless participants and those in transitional housing exposed the exclusive and unrealistic stereotype that older people reside comfortably in a long-term residence. Their experiences countered assumptions that older individuals desire and expect to age in place in a familiar home environment of their choosing for as long as possible (e.g. Wahl et al., 2012). Financial resources impacted the ability to stay put and choice of living situation (Wahl and Oswald, 2016). Participants without stable housing expressed statements of anxiety and insecurity because of their transient residential situations. Mary (66, Downtown Minneapolis) had only recently secured a government-subsidised apartment after a workplace injury caused her to lose her job: 'In a moment, your whole life changes. You lose your job, you lose your income, you lose your home, you lose your savings. It was a nightmare, all of it. I'm still recovering.' Displacement was traumatic. Those in unstable situations desperately wanted more long-term, secure and autonomous living accommodation. They exhibited unequal access to and uneven opportunities for place attachment given unexpected life circumstances and resource limitations.

Further, the home was not necessarily an extension of the self. Experiences in subsidised housing emphasised prohibitive rules that restricted a 'homey' atmosphere. Apartments were not necessarily central gathering points or repositories for treasured memories (Gieseking et al., 2014). Some participants could not inhabit residential spaces in a way to make them feel like home. Personal space in subsidised housing was routinely violated with mandatory home inspections and restrictive rules against modifications and decorations. These restrictions limited the creation of a homey autonomous space, and made some participants feel 'stuck in place' without the financial resources to relocate to more comfortable 
and secure living situations. Elective belonging (Phillipson, 2007) was not an option for all participants. When the researchers entered subsidised apartments, participants often apologised for the bare or outdated surroundings. They expressed frustration at the lack of autonomy and minimal level of personalisation allowed in the home. Participants stated desires to replace carpeting, repaint and refurnish to feel more comfortable, such as installing a softer carpet underfoot for arthritic joints.

Ambient sounds of yelling, banging and gunshots, as well as being robbed by neighbours, made some participants feel defenceless and insecure. Richard (77, Downtown Minneapolis) explained on his mobile interview: 'There's been robberies and attacks right outside here. Right outside. In fact, one of the residents was severely beaten and robbed right here.' As a result of his fears, Richard was largely homebound and did not enjoy living in his apartment. He felt unsafe and desperately wanted to move back to South-East Asia in order to be closer to his friends and youthful aspirations. His situation countered assumptions of the home as an anchor of identity and source of wellbeing (Hay, 1998). Socio-economic barriers limited Richard's ability to achieve continuity and control over his domestic situation and optimise place attachment. Ageing in place for some was an isolated and precarious existence (Aldwin and Igarashi, 2012; Finlay, 2018; Finlay and Kobayashi, 2018).

The homeless participants in Downtown Minneapolis felt keenly vulnerable to their surroundings. Their safety strategies included queuing for early entry to the shelter and going to sleep in the late afternoon to avoid rowdy night-time crowds. Ian (60, Downtown Minneapolis) locked himself in his small single room at the homeless centre by dusk and did not use the communal bathroom at night to avoid the regular fights and crime just outside in the hallways. Iris (68, Downtown Minneapolis) bounced between hospitals, group homes and homeless shelters since eviction from her last apartment for hoarding. Living in her current shelter for the past seven months, Iris struggled to feel comfortable or safe. She had not showered due to the lack of secure women's facilities:

They have one room for the men, and then way over there (indicating a room approximately ten metres away) another room for the women. We eat together, but then men want to stay in the dining room and always come into the women's room. I have to walk from here all the way to over there (indicating a room approximately 20 metres away) to go to the bathroom. That's no privacy. I haven't taken a bath since I've been here because there's no privacy. [I'm] waiting [to shower] until I get a place because I don't trust it. There's no privacy.

As a result of physical and emotional insecurity, Iris stated that there was 'no point' in conducting the mobile interview because 'nowhere around here matters'. She travelled daily around downtown in search of free meals from churches and charity organisations. The shelter was a constant source of distress and restricted autonomy: 'I'm sad I'm in this shelter. I can't do what I want to do.' Because of repeated evictions, Iris was barred from moving back into Minneapolis public housing. Lack of security and safety were constant sources of frustration, disappointment and fear. Both Iris and Ian desperately wanted their own private apartments and reliable places to call home (Wahl and Oswald, 2016). The inability to own or rent a 
home, and thereby participate in normative civic life (Hayden, 1995), inhibited the cultivation of residential belonging 'in place' (Relph, 1976).

\section{Adjusting to adversity}

Downtown Minneapolis participants expressed feeling safer with building security features such as cameras and locked entryways. In North Minneapolis, participants similarly mentioned locked doors, alarm systems and night-time lighting that made them feel safer. Residents with a weak sense-of-place felt unsafe living in close proximity to drug trafficking, crime incidents and foreclosed lots. Shirley (72, North Minneapolis), a recent immigrant in subsidised housing, noted: 'The neighbourhood's no good. Too much drinking, fighting, smoking, using abusive language. It's not good. People drive by shooting at things.' Shirley's fearful situation represented a temporary situation while she tried to sort out a better residence. She did not feel that it was a good place for her or other older individuals, but given severely restricted finances had no other options. Her observations reflect Blokland's (2008) study of place-making in New Haven (Connecticut) housing projects, where home - a connection and rootedness to one's place of dwelling - is routinely denied, especially to the poor and people of colour in Western settings. Shirley felt unsafe and lost, which meaningfully limited opportunities to feel rooted in place'. Structural issues and social injustice impacted opportunities to live in stable, safe and comfortable homes.

Long-term North Minneapolis residents expressed that a certain level of vandalism and petty theft was normal and felt unperturbed by minor incidents. Long-time resident Timothy (77, North Minneapolis) explained: 'Doesn't make a difference what neighbourhood you live in, you're going to have some type of vandalism.' Participants strategically invoked memory and imagination to cultivate a sense of belonging and a re-assuring sense of living in a 'good place'. Timothy overlooked local crime hotspots and dilapidated services to focus instead on the strengths of his community. He fondly pointed to worn-down storefronts during the mobile interview and remembered the corner store as a familiar sight of childhood summer trips for soda, teenage employment and milk runs as a young parent. The nowclosed barbershop was still vibrant in Timothy's mind as it cohered warm memories and youthful ambitions. Participants referenced a plethora of 'incident places' that spanned their entire lifetimes and contributed to a rich and comforting sense of autobiographical insideness (Rowles, 1983). The quality and intensity of these reflections helped Timothy maintain a largely positive connection to his local environment. He exemplified a strong sense of belonging (Wahl et al., 2012) through subjective evaluations and selective emotional interpretations of the immediate neighbourhood.

For widows now living alone, however, this sense of safety could diminish. Participants such as Millie (78, North Minneapolis) felt frightened and unsettled by house break-ins. Her neighbourhood had socio-economically declined with the intrusion of transient renters, crime and abandoned lots. Now alone at home, Millie felt invaded and her sense of security reduced. The police were disinterested in her following up on calls and complaints. The physical and social neighbourhood setting no longer corresponded to her needs or identity, yet she felt defensive about remaining 'in place'. Millie anxiously weighed deep-rooted 
affection for her home against the safety risks and lack of responsive emergency services.

\section{Service access}

Participants discussed local amenities as essential residential elements, including grocery stores, medical sites, senior centres, gyms, coffee shops, retail locations, libraries, post offices and public transit. They were important everyday reference points in participants' lives (Gieseking et al., 2014), and imbued senses of belonging, interpersonal connection and purpose.

\section{Vital locations}

Retail and recreation sites were essential activities and destinations built into everyday habit. Service destinations not only functioned practically; they were also primary sources of entertainment, sites of comfort and belonging, and reasons to 'get out the door'. Senior centres in Eden Prairie and Downtown Minneapolis were valued locations to gather and interact with others, learn new skills and have fun. Male participants especially mentioned these locations, such as spending every weekday morning in the woodshop 'with the guys' seeking companionship and purpose. Retail sites were vital to individuals such as Brenda (73, Eden Prairie): 'If I get really depressed or down, I leave the building. Get in my car and go. I go to a lot of thrift shops, [food shelves], Goodwill, or just browse around [the local department store].' Brenda felt 'at home' in these shops where she was greeted by familiar employees and storefronts. She transformed local retail spaces into meaningful places, and through regular visits developed insider status (Hay, 1998). Grocery stores and coffee shops were similar sites of entertainment and connection, and participants often went every week. Such trips represented an affordable stimulation strategy and method to connect with others: employees and staff, regular customers, neighbours and ambient multigenerational contact. Opportunities to build social relationships cultivated a rooted sense-of-place in varying geographic locales (Low and Altman, 1992; Hay, 1998).

Sense of community and interconnection through local sites enabled everyday life 'in place' (Kyle and Chick, 2007; Scannell and Gifford, 2010). Affection and rooted connection to a local coffee shop shone through Rachel's (74, Downtown Minneapolis) mobile interview. Rachel lived alone and was estranged from her children. She found community through the little coffee shop on her block. After walking in, the staff greeted Rachel with familiarity and warmth. An employee immediately began her usual coffee and cookie order while asking about her upcoming dentist appointment and opinion about a nearby art show. Rachel frequented the coffee shop daily, accumulating a monthly tab that she paid immediately after her welfare cheque arrived. This shop represented a site of comfort, care and attention, and one of the primary reasons she enjoyed her apartment and wanted to remain living there. Rachel mentioned memory concerns and struggled to live alone. Rotting food, dirty surfaces and perilous stacks of belongings flagged researchers' attention to her perilous living situation. Despite these risks, Rachel planned to 'live to 100' years old in the apartment. She was content with her situation given the coffee shop downstairs and two grocery stores within walking 
distance. These observations complicate assumptions that place attachment is fundamentally good. Due to a deep sense of belonging, Rachel put herself at risk to remain in her apartment. She and others prioritised rootedness and insider status even in sub-optimal living conditions and hazardous residential situations.

\section{Limited options}

In North Minneapolis, participants were frustrated by the lack of nearby grocery stores. Jeremy (72, North Minneapolis) reported the dearth of nutritious food services: 'If you're living on Mountain Dew and potato chips, you're fine. If you're looking for fresh fruit and vegetables, lean fresh meats ... it's much harder to do.' In this food desert (Cummins and Macintyre, 2002; Walker et al., 2010), fast food, convenience stores and liquor outlets were dominant, with participants travelling downtown or further into the suburbs for groceries. Jeremy was focused on his health given recent scares: 'I spend a lot of time trying to eat well, exercise, be healthy and make healthy choices so that my quality of life will stay good for as long as possible. That's where I spend my energy.' He felt increasingly unsatisfied by the lack of local healthy food options and pessimistic about the suitability of his neighbourhood.

Participants expressed further frustration at the shortage of amenities and lack of investment in North Minneapolis' low-income areas. In addition to grocery stores, this included a dearth of coffee shops, cafes and restaurants. Raquel noted:

There are a lot of seniors that are our friends who are isolated. I think it's because we don't have places where you can just go sit down, have a cup of coffee, see who comes in, visit with one another. (Raquel, 74, North Minneapolis)

The lack of services was a barrier to cultivating a sense of inclusion, belonging and enjoyment in the community. One exception was a newly opened YMCA with a senior-specific gym and exercise classes. Ingrid explained:

They built a YMCA for us 50-plus ... The people there, we're all older. It's just like a big social club. We work out, but we also laugh and have fun. It's just a bunch of old people getting together and hanging out. I always felt that laughter is very healthy for you. I feel rejuvenated going there, both mentally and spiritually. It's just like a safe haven to go to, plus we get healthy. (Ingrid, 66, North Minneapolis)

Participants visited 'the Y' for exercise, and to socialise with fellow attendees and friendly staff. They appreciated the culturally relevant and age-appropriate services offered to local African American residents. Churches across North Minneapolis also provided meaningful connection and belonging through a network of services and support for residents. Members stated that their faith communities 'look out for you' and 'check in' on a regular basis. Participants both provided and received supportive services such as rides, meals, luncheons, organised activities and grief counselling through their churches. Local organisations, shops and centres catering to seniors contributed meaningfully to feeling able to age well in the home and community. Participants cultivated place attachment to multiple locations beyond their homes and immediate environments. They leveraged local community 
strengths, including the YMCA and churches, to overcome disadvantages such as the lack of grocery stores and coffee shops.

\section{Social connection}

Local social networks enabled participants to feel rooted in the community and happy with their living situations. Nearby family, friends and opportunities for purposeful and ambient contact generated social insideness (Rowles, 1983).

\section{Essential community}

Participants such as Raquel (74, North Minneapolis) cultivated strong friendship groups and felt firmly embedded in the local social fabric. Raquel relied on a network of close friends during widowhood:

I have very good friends. I've been widowed since 1978, and had I not had those friends, it would have been very difficult for me. And then they're like family ... very close good friends that care about you.

Overall, North Minneapolis participants reported the lowest levels of isolation and loneliness. Primarily African American, these participants were often deeply entrenched socially and enfolded within local multigenerational networks. They reported satisfaction from regular interactions with grandchildren, family, friends, neighbours and community members. Racial inclusiveness was a valued element. Participants purposefully chose homes in the diverse area, and stated desires to continue living in a racially inclusive community. Harmonious living enabled participants to cultivate mutual identification with a community of shared group morals, norms and expectations (Rowles, 2017).

Long-time residents were fiercely proud and passionate about their community, and expressly rejected what they viewed as unfair media portrayals and negative racial stereotypes of North Minneapolis. Both African American and White North Minneapolis residents felt that it was the ideal place to live given the robust multiracial and multigenerational community. This resilient attitude was common among long-term residents and those enmeshed within strong family networks. Sally (67, North Minneapolis), for example, had supportive neighbours and immediate family who helped with chores, transportation and watched out for each other: 'I know everybody in [my neighbourhood]. No one will mess with you, we're just like family, we really are. Everybody helps each other.' These participants relied upon a web of supportive community connections and 'common sense' to feel secure and interconnected. Participants benefited from intimate social and cultural networks built up over time. This led to concern about having to move due to declining health and independence, and the incumbent social and emotional upheaval. Without suitable age-friendly housing stock (e.g. one-floor apartments), assisted living or appropriate services in North Minneapolis, there were limited opportunities to age 'in community'. What was 'good' about the community - leafy streets, single-family homes, quiet neighbourhoods - were age-specific to accommodate earlier phases of life. Participants worried that the neighbourhood could not physically accommodate changing needs, and that they would burden family members. Participants requested that affordable, age-friendly, one-floor apartments 
and assisted living options be built to enable them to remain in the community close to kin.

\section{Struggles to stay connected}

Participants living geographically far away from family and friends struggled with loneliness and felt less rooted 'in place'. Several female participants in Downtown Minneapolis and Eden Prairie moved to be closer to their children and expressed the heartache of missing their 'real home' and long-time friends. They lamented at how difficult it was to be a transplant and break into already-existing social groups, which lowered residential satisfaction. Built form affected opportunities for socialisation, such as shared hallways and courtyards in apartments to regularly interact with neighbours versus more-isolating single-family homes. Participants in high-rise buildings took advantage of elevator conversations with neighbours and building staff (Finlay and Kobayashi, 2018). They appreciated maintenance and social workers who provided social stimulation and support.

Harsh weather, including intense summer heat and winter snow, challenged participants' abilities to stay connected and content. Participants curtailed activities to only necessary trips during inclement weather to ensure their safety, which diminished opportunities for socialisation (Finlay, 2018). Rebecca (77, Downtown Minneapolis), for example, felt cooped up and was afraid to venture outside. She was afraid to walk outside on the ice but felt 'very trapped' and 'bored to tears staying home'. Rebecca occupied a unique position: her building was previously entirely subsidised housing and then transitioned into high-end market rentals. Rebecca lived in one of 20 units still subsidised, and knew that she had 'won the lottery' to be a low-income woman living in a luxurious apartment building. Yet Rebecca was desperately unhappy and preferred the old entirely subsidised model because of the organised social activities and sense of community. She previously felt 'at home' and connected to other residents, with all of her needs accommodated. Rebecca expressed feeling foolish at her desire to move into less-nice subsidised housing, but emphasised that community and companionship were her top priorities.

A major fear for isolated individuals such as Betty (78, North Minneapolis) was dying alone: 'What I am most afraid of is that I die inside my home, without anybody else living here or coming to the house, and that they won't find me until I've been decomposing for a few days.' To combat this, Betty and others developed buddy-systems with friends and family. They checked on each other regularly through phone calls and visits to feel more comfortable and safe. Pets also provided comfort and companionship. Participants stressed the importance of living somewhere that afforded regular social interaction and interpersonal connection.

\section{The tipping point}

One's level of social connectedness often represented a 'tipping point' for participants dealing with challenges of the built environment. They did not have the resources of more affluent participants to invest in social strategies such as seasonal travel to warmer destinations, restaurant meals with family and cultural events with friends. When low-income participants felt isolated and unsupported, they tended to feel unhappy with their residential situation and advocated for moving. Lack of 
social insideness (Rowles, 1983) was crippling. Shannon (71, Downtown Minneapolis), for example, was fed up with the smoke infiltration and vermin infestation of her subsidised apartment building. Her frustration multiplied after her daughter moved out and she no longer had any friends in the building. Feeling separated, alienated or excluded - what Relph (1976) termed outsideness - undermined residential wellbeing. Conversely, those with robust social connectedness overlooked and overcame built environment challenges. The elevator in Frank's (77, Downtown Minneapolis) building often broke and he could not climb the seven flights of stairs safely. Though the building did not accommodate his physical needs, Frank thought that it was an ideal location for him because he had cultivated a valuable network of friends and relationships in the building and local area. He desired to maintain 'rootedness' despite sub-optimal living conditions (Fang et al., 2016).

Ingrid (66) lived in a dilapidated North Minneapolis house with moulding walls, gapped floorboards and broken concrete steps. She overlooked this and considered it a good place to live because of her long-time community:

I'm comfortable. I feel safe here. I was born here - I'm probably only three or four miles away from where I grew up. I know lots of people. My church is here; my whole life is here.

The proximity and depth of social connections were major factors in any sense of rootedness and satisfaction with living situation despite physical risk. Participants such as Ingrid remained rooted in places that had changed and disintegrated over time, presenting daily fall hazards and health risks. Ingrid refused to consider leaving her decaying home due to an unwillingness to abandon long-cultivated insideness. She perceived that to abandon the home would be to give up her identity (Rowles, 1983). In fact, the physical decay of Ingrid's home precipitated even stronger emotional attachment to the home as she felt defensive of the house so tied to her self-identity (Proshansky et al., 1983). Ageing in place thus produced hazardous situations for some with sub-standard housing and lack of appropriate support.

\section{Stimulation}

Participants cultivated well-honed routines in and around their homes and immediate neighbourhood. Fulfilling and meaningful habits were vitally important to residential satisfaction and development of place attachment.

\section{Everyday routines}

Small-scale activities such as reading, writing, knitting, cooking, gardening, watching television, talking on the phone and receiving/providing care meaningfully filled the day. Participants often recounted daily migration through the home at uniform and regulated times - such as Warren (65, Eden Prairie) who ate 'breakfast at 7 o'clock in the kitchen, followed by reading the newspaper in the sunny front room, 11 o'clock lunch, afternoon chores and 3 o'clock tea in the shady back room'. He felt immensely happy to enjoy his own space after successfully applying for a first-time home-owner's subsidy. He alluded to the importance of a familiar and comfortable environment with reliable spatial and temporal structure. 
Participants honed rich micro-geographies around their homes. Nicola and Steve (both 85, Eden Prairie) demonstrated their deep residential attachment during the mobile interview. Due to Steve's severe mobility limitation, they provided an interior tour. Steve took frequent breaks in chairs strategically placed throughout the home. They spoke emotionally of treasured belongings, sentimental artwork and family photographs. Their accumulated lives were on display as Steve 'do[es] more remembering than doing' these days. He expressed contentment to surround himself with pictures of grandchildren, friends and departed loved ones. Autobiographical insideness (Rowles, 1983) reverberated through Nicola and Steve's mobile interview as they paused frequently to discuss the photographs and memories of the people and places that shaped their lives. Rich cognitive and affective ties to home instilled a sense of identity, purpose and a meaningful life (Kyle and Chick, 2007; Scannell and Gifford, 2010).

Participants found reasons 'to get up in the morning' through routines around their neighbourhoods and broader communities. Sally (67, North Minneapolis) went to great effort to keep busy despite a pinched nerve and diminished mobility. She began organising regular trips on assisted transit after her husband passed away: 'It helps me keep going. I think now if I didn't do this, I would probably be crippled. Just sitting around doing nothing. I have to get out.' These efforts helped her maintain a sense of connection and purpose in her local community. Sally and many others stated their reliance on affordable and free activities given limited resources. They particularly appreciated subsidised rates for public transit and recreational amenities.

Walking was a common everyday activity, and therefore a component of residential satisfaction for many participants. Supportive street and neighbourhood elements, as well as nearby destinations (e.g. parks, stores, landmarks), facilitated walking for recreation and utilitarian purposes. Participants with impaired eyesight, hearing and mobility felt more vulnerable to the built environment. They particularly appreciated pedestrian accommodations including longer-timed crosswalks, smooth curb cuts (sidewalk ramps), sturdy handles and railings, 'skyways' and covered bus stop shelters. Outdoor activities such as gardening decreased boredom and boosted quality of life. Participants appreciated small-scale features, including pocket parks, shaded benches and local wildlife (e.g. birds, squirrels, deer). Indirect exposure, such as views through a window in the home, offered stimulation and enjoyment - particularly for those with mobility limitations (Finlay et al., 2015).

\section{Enduring hardship}

Those without long-term or autonomous housing could cultivate meaningful routines, connections and place attachment. Iris (68, Downtown Minneapolis), for example, countered her lack of stable housing and unsafe homeless shelter by focusing on her positive connection to the downtown senior centre. Iris travelled there daily to take advantage of the free snacks, socialise with peers, and enjoy a safe and supportive environment. She made friends and appreciated experiences of belonging. When she arrived each day, Iris entered into her community to belong, see, do, help and be cared for (Cutchin, 2003). The senior centre was a spatial metaphor for home: the enduring place in which Iris felt that she belonged (Imrie, 2004). 
Denise (72, Eden Prairie) was distressed that disability following a stroke and limited resources kept her cooped up:

I wish I could get around. I wish I could walk over to [the lake]. I've always done a lot of hiking for vacations. It never dawned on me that I wouldn't be able to drive or walk. That's not fair.

Denise wanted to live in a building with more amenities, services and entertainment; but lack of resources made this difficult or impossible to achieve. She felt unhappy with her residential situation, but did not want to become overly anxious or distressed. Denise instead entertained herself with plants on the windowsill, knitting when her arthritis permitted and mailed books from the local library. She sought out meaningful activity and crafted fulfilling routines in a resilient manner. Denise had a history of frequent moves depending on variable finances and health status. Her set of family photographs and memorabilia carefully moved with her each time. Each environmental change involved a process of transference of being 'in place' (Rowles, 2017): Denise felt 'at home' in whatever space (e.g. hospital, nursing home, new apartment) as long as she had these significant objects. In creating place attachment and a sense of home, these cherished objects (and the memories and routines attached to them) were more important than the physical space itself or duration of residence (Aldwin and Igarashi, 2012; Wahl and Oswald, 2016). The personal artefacts enabled Denise to feel competent, in control of and personally connected to her living environment despite economic and functional limitations (Cutchin, 2003; Golant, 2011). Denise determinedly developed 'at homeness' (Seamon, 1979) by seeking out comforting and familiar surroundings and objects. They were essential to routine and identity.

\section{Negotiated ageing 'in place'}

Socio-economically marginalised individuals more often inhabit and endure degraded, under-served and unsafe residential environments (Sallis et al., 2011). This research demonstrates how low-income older adults are especially susceptible to deprived and hazardous spaces given their embodied vulnerabilities and limited resources. From sitting on the floor of a homeless shelter to witnessing a drug deal while walking along a downtrodden street (Finlay and Bowman, 2017), the qualitative methods documented terrain and struggles that often remain unexamined. This made room for difference in geographical gerontology by recognising more diverse standpoints and contexts of later life.

Home traditionally incorporates ideas of permanence, ownership, privacy, refuge, comfort, autonomy and identity (Rowles and Chaudhury, 2005). We expect that one has increasing capability over the lifecourse to cultivate place attachment at home through well-honed routines, accumulated possessions and meaningful events that transpire in this location (Rowles, 2017). Geographical gerontology tends to assume that most ageing individuals have cultivated a strong sense of insideness; having lived in their homes a long time, the furniture, layout and belongings represent treasured memories and contentment. This follows an idea of elective belonging (Phillipson, 2007), whereby people seek to inhabit places that mirror their identities and preferences. Yet the findings from this study 
demonstrated that not all individuals have the resources or even desire to be selective about their residential environments. Elective belonging is predicated upon a privileged perspective. Socio-economic status meaningfully limited choice of living situation and ability to stay put (Wahl and Oswald, 2016). Participants described years of living in deprived and disadvantaged homes and neighbourhoods. Prohibitive settings, including rules imposed in homeless shelters and subsidised housing, limited the ability to intentionally construct a sense of home. Transitory lifestyles, voluntary moves and forced mobility to geographically dispersed locations countered normative assumptions of lifelong familiarity within a locale (Rowles, 1983). Altogether, the findings problematise existing place attachment scholarship that assumes older adults have stable housing and secure economic resources. They concretely illustrate how place attachment is not inherently positive nor necessarily attainable according to current conception.

In addition to instances of place-based victimisation and harm, the findings also highlighted creative ways that participants negotiated around deprivation and neglect. Individual resourcefulness and resiliency enabled participants to cultivate localised meaning and belonging. Participants navigated material and socio-economic barriers to construct physical, social and psychological dimensions of home and community. Limited budgets, for example, led participants to engineer low-cost modifications like a chair in the shower and furniture strategically placed around the house to prevent falls. Subsidised housing recipients navigated around restrictive rules to develop a comforting home environment through photographs, taped decorations, sentimental knick-knacks and family artwork. Participants resourcefully cultivated support networks through neighbours, friends, family and professionals. They exercised agency through 'reactive and proactive aspects of using, compensating, adapting, retrofitting, creating, and sustaining places' (Wahl et al., 2012: 309). Participants negotiated a complex geographical process of agency and belonging to resiliently achieve a sense of belonging, autonomy, independence and safety. Generating insideness was an active and creative process (Rowles, 2017).

A resilient stance involved some trade-offs, such as Millie's (78, North Minneapolis) prioritisation of social connection and stimulation. She was firmly rooted in her home and felt that this was overall the best place for her despite poor safety and service access. The neighbourhood had changed around her as it declined socio-economically with transient renters, an influx of drug deals and petty crime, and abandoned lots. Millie's favourite stores down the block were permanently closed and the street was no longer a thriving site of families and mowed lawns. Millie's memories of the neighbourhood and emotional attachment to her long-time home prevented her from moving into safer and more accommodating settings. She was attached to a self-created place that was now a fictional remnant of the past (Rowles, 1983). Vivid memories of the neighbourhood as prosperous and socially alive caused Millie to colour her image of the present with a more positive hue. Her idiosyncratic sense of autobiographical insideness was so strong that it masked the growing risk of remaining 'in place'. These observations prompt critical re-evaluation of place attachment given the vulnerabilities and structural inequalities that it can expose and exploit.

There are limitations to the generalisability of findings. Minneapolis is generally supportive to older adults through heavy investment in services and support, 
natural infrastructure, care provision, nursing homes and active transit. The 'skyways', for example, are a unique feature that enable downtown pedestrian mobility shielded from weather and traffic. Experiences will vary widely in other geographic areas with distinct political, economic, socio-cultural and natural climates. The interviews were conducted from June to October and did not occur during winter months; though many participants still discussed experiences of ice, snow and frigid temperatures (Finlay, 2018). The project was further limited by sampling to analyse by age (e.g. younger versus older participants in the study), race/ethnicity or socio-economic status within each geographic area. The non-random fixed quota sampling over-sampled White populations in Downtown Minneapolis and Blacks/ African Americans in North Minneapolis. The study encompassed a range of urban and suburban settings, but did not include any rural areas, institutional settings or care environments. Given these limitations, the study illuminates a limited set of realities for older adults living across the Minneapolis metropolitan area. These results should be considered hypothesis-generating and prompt further exploration in different geographic settings, purposefully sampled socio-economic communities and longitudinal studies.

\section{Conclusions and future directions}

The research contributes to and broadens geographical gerontology by focusing on a wider set of experiences and perceptions of place-making among low-income individuals. It exposes lived experiences and contexts of ageing that are often overlooked with issues such as financial deprivation, transient housing, commercial disinvestment and social isolation coming to the forefront. In an era of privatisation, extreme inequalities and concentrated zones of affluence and poverty, this article seeks a more accurate and inclusive theoretical foundation in geographical gerontology.

Diversity to date is primarily treated as inter-individual differences at the person level; relatively little is known about the ways in which person-place interactions vary by cohort, culture, socio-economic status and other contextual variables (Scharlach and Diaz Moore, 2016; Wahl and Oswald, 2016). This study pushes the field to focus on more diverse communities and critically unpack starkly uneven opportunities to reside in 'a good place to grow old'. This involves attention to older adults across the entire socio-economic spectrum in urban to rural contexts. The debilitating lack of services in low-income urban areas, for example, may produce similar harms among even affluent individuals ageing in rural areas. Critical attention to different groups of older adults will further unpack nuances of how socio-spatial needs and experiences differ and overlap among older adults.

Furthermore, there is a need to develop new models of study and intervention in geographical gerontology that reflect and respond to the very different global contexts in which people grow old. Less-developed countries have burgeoning ageing populations. Future efforts will require the study of changing dynamics of poverty, consequences of urban renewal and regeneration, and growing transnational mobilities among ageing populations (Buffel and Phillipson, 2016). Careful intersectional examination (Crenshaw, 1993) of race, class, gender, sexuality, culture and other social categories that overlap with old age will expand 
understanding of diverse approaches to ageing in place'. Varied articulations of feeling safe, supported and socially connected in this study demonstrated the inappropriateness of 'one-size-fits-all' approaches to residential wellbeing.

Applied methods drawing from participatory research will aid geographical gerontologists to produce knowledge with and for those most in need. Older adults are best positioned to identify their own areas, prioritise age-friendly design issues and guide appropriate implementation (Menec et al., 2011). Geographical gerontology needs to engage traditionally under-represented and vulnerable elders including the impoverished, racial and ethnic minorities, transient, disabled, isolated, and physically and mentally unwell. Using an approach grounded in everyday experience, disadvantaged older adults can share a platform with researchers to broaden theoretical conceptions and discuss ways of facilitating positive change (Fang et al., 2016). This will generate novel opportunities for geographical gerontology to address growing inequities and reimagine ageing 'in place' along more inclusive and socially just lines.

Acknowledgements. The authors are indebted to the participants in this research study who so openly shared their homes, knowledge and experiences. Contributing research assistants included Jay Bowman, Joann Khong, Jessa Hohnstein and Alec Trenda. Thank you to Colleen Peterson, Lauren Mitchell, the anonymous reviewers and editor for helpful reviews of the manuscript. Finally, we are grateful to Dr Bob Kane who was a tireless advocate for older adults and staunch supporter of fledgling gerontologists.

\section{Notes}

1 Text in parentheses following a participant's pseudonym represents his or her age and case study area of residence at the time of research.

2 The project's initial age minimum was set to 65 . Within the first two weeks of recruitment, JF was contacted by numerous individuals aged 55-64, particularly from Downtown Minneapolis and North Minneapolis, who self-identified as an 'older adult' and desired to participate. JF submitted a change in protocol to the Institutional Review Board in order to include these individuals in the study.

Author contributions. All authors were substantially involved in the design, analysis and drafting of this paper. Dr Robert Kane sadly passed away during the process of revisions.

Financial support. This research was supported in part by a grant from the National Science Foundation (grant number 1558577).

Conflict of interest. There are no conflicts of interest to declare.

Ethical standards. The study was approved by the University of Minnesota Institutional Review Board (1410P54782).

\section{References}

Administration for Community Living (2018) Administration on Aging Profile of Older Americans 2017. Washington, DC: US Department of Health and Human Services. Available at https://www.acl.gov/ aging-and-disability-in-america/data-and-research/profile-older-americans.

Aldwin C and Igarashi H (2012) An ecological model of resilience in late life. Annual Review of Gerontology and Geriatrics 32, 115-130.

Blokland T (2008) 'You got to remember you live in public housing': place-making in an American housing project. Housing, Theory and Society 25, 31-46.

Braun V and Clarke V (2006) Using thematic analysis in psychology. Qualitative Research in Psychology 3, 77-101. 
Buffel T and Phillipson C (2016) Can global cities be 'age-friendly cities'? Urban development and ageing populations. Cities 55, 94-100.

Crenshaw KW (1993) Beyond racism and misogyny: Black feminism and 2 Live Crew. In Matsuda MJ, Lawrence CR, Delgado R and Crenshaw KW (eds), Words That Wound: Critical Race Theory, Assaultive Speech, and the First Amendment. Boulder, CO: Westview Press, pp. 111-132.

Cummins S and Macintyre S (2002) 'Food deserts' - evidence and assumption in health policy making. British Medical Journal 325, 436-438.

Cutchin MP (2003) The process of mediated aging-in-place: a theoretically and empirically based model. Social Science \& Medicine 57, 1077-1090.

Dey I (1999) Grounding Grounded Theory: Guidelines for Qualitative Inquiry. San Diego, CA: Sage.

Fang M, Woolrych R, Sixsmith J, Canham S, Battersby L and Sixsmith A (2016) Place-making with older persons: establishing sense-of-place through participatory community mapping workshops. Social Science \& Medicine 168, 223-229.

Finlay JM (2018) 'Walk like a penguin!': older Minnesotans' experiences of (non)therapeutic white space. Social Science \& Medicine 198, 77-84.

Finlay JM and Bowman JA (2017) Geographies on the move: a practical and theoretical approach to the mobile interview. The Professional Geographer 69, 263-274.

Finlay JM, Franke T, McKay H and Sims-Gould J (2015) Therapeutic landscapes and wellbeing in later life: Impacts of blue and green spaces for older adults. Health \& Place 34, 97-106.

Finlay JM and Kobayashi L (2018) Social isolation and loneliness in later life: a parallel convergent mixedmethods case study of older adults and their residential contexts in the Minneapolis metropolitan area, USA. Social Science \& Medicine 208, 25-33.

Gieseking JJ, Mangold W, Katz C, Low S and Saegert S (eds) (2014) The People, Place, and Space Reader. New York, NY: Routledge.

Golant SM (2011) The changing residential environments of older people. In Binstock RH and George LK (eds), Handbook of Aging and the Social Sciences, 7th Edn. Burlington, MA: Elsevier, pp. 205-220.

Hay R (1998) Sense of place in developmental context. Journal of Environmental Psychology 18, 5-29.

Hayden D (1995) The Power of Place. Cambridge, MA: MIT Press.

Heatwole Shank KS and Cutchin MP (2016) Processes of developing 'community livability' in older age. Journal of Aging Studies 39, 66-72.

Imrie R (2004) Disability, embodiment and the meaning of the home. Housing Studies 19, 745-763.

Kyle G and Chick G (2007) The social construction of a sense of place. Leisure Sciences 29, 209-225.

Lamke S (dir.) (2011) Cornerstones: A History of North Minneapolis. TPT Documentaries. Minneapolis, MN: Twin Cities PBS.

Low SM and Altman I (1992) Place Attachment: A Conceptual Inquiry. New York, NY: Plenum Press.

Marshall C and Rossmann G (2016) Designing Qualitative Research, 6th Edn. Newbury Park, CA: Sage.

Menec VH, Means R, Keating N, Parkhurst G and Eales J (2011) Conceptualizing age-friendly communities. Canadian Journal on Aging 30, 479-493.

Nagourney A (2016) Old and on the street: the graying of America's homeless. The New York Times, May 31. Available at https://www.nytimes.com/2016/05/31/us/americas-aging-homeless-old-and-onthe-street.html?_r=1.

Phillipson C. (2007) The 'elected' and the 'excluded': sociological perspectives on the experience of place and community in old age. Ageing \& Society 27, 321-342.

Proshansky HM, Fabian AK and Kaminoff R (1983) Place-identity: physical world socialization of the self. Journal of Environmental Psychology 3, 57-83.

Relph E (1976) Place and Placelessness. London: Pion.

Rowles GD (1983) Place and personal identity in old age: observations from Appalachia. Journal of Environmental Psychology 3, 299-313.

Rowles GD (2017) Being in place, identity and place attachment in late life. In Skinner M, Andrews G and Cutchin M (eds), Geographical Gerontology: Concepts and Approaches. New York, NY: Routledge, pp. 203-215.

Rowles GD and Chaudhury H (eds) (2005) Home and Identity in Late Life: International Perspectives. New York, NY: Springer. 
Sallis JF, Slymen DJ, Conway TL, Frank LD, Saelens BE, Cain K and Chapman JE (2011) Income disparities in perceived neighborhood built and social environment attributes. Health \& Place 17, 12741283.

Scannell L and Gifford R (2010) Defining place attachment: a tripartite organizing framework. Journal of Environmental Psychology 30, 1-10.

Scharlach A and Diaz Moore K (2016) Aging in place. In Bengtson V and Settersten R (eds), Handbook of Theories of Aging. New York, NY: Springer, pp. 407-425.

Seamon D (1979) A Geography of the Lifeworld: Movement, Rest and Encounter. New York, NY, St. Martin's Press.

US Census Bureau (2015) QuickFacts. Available at https:/www.census.gov/quickfacts/table/PST045216/00.

Wahl HW, Iwarsson S and Oswald F (2012) Aging well and the environment: toward an integrative model and research agenda for the future. The Gerontologist 52, 306-316.

Wahl HW and Oswald F (2016) Theories of environmental gerontology: old and new avenues for personenvironmental views of aging. In Bengtson V and Settersten R (eds), Handbook of Theories of Aging. New York, NY: Springer, pp. 621-641.

Walker RE, Keane CR and Burke JG (2010) Disparities and access to healthy food in the United States: a review of food deserts literature. Health \& Place 16, 876-884.

Cite this article: Finlay JM, Gaugler JE, Kane RL (2020). Ageing in the margins: expectations of and struggles for 'a good place to grow old' among low-income older Minnesotans. Ageing é Society 40, 759-783. https://doi.org/10.1017/S0144686X1800123X 